\title{
Predation and survival in reintroduced populations of the Common hamster Cricetus cricetus in the Netherlands
}

\author{
Maurice J. J. La Haye ${ }^{1,2}$ (D) Ruud J. M. van Kats ${ }^{2} \cdot$ Gerard J. D. M. Müskens ${ }^{2} \cdot$ Caspar A. Hallmann $^{1}$ (1) \\ Eelke Jongejans ${ }^{1}$ (I)
}

Received: 28 January 2020 / Accepted: 29 August 2020 / Published online: 16 September 2020

(c) The Author(s) 2020

\begin{abstract}
European populations of Common hamster (Cricetus cricetus) have dramatically declined in the last decades, and in many EU countries, the species is on the brink of extinction. In the Netherlands, a research and reintroduction program was started in three areas with hamster-friendly management to reverse the decline of the species. Since 2002, more than 800 captive-bred and wild-born hamsters were monitored using implant radiotransmitters to quantify survival rates and discover the main causes of death after release compared to those of wild individuals. Individuals with a transmitter were regularly checked at their burrow. Predation by foxes, birds of prey, and small mustelids was the most important cause of mortality of this medium-sized rodent, while crop type and harvest regime were also likely to be important drivers as they influenced survival rates through the presence or absence of protective cover. The fitted weekly survival model showed that male hamsters had much lower survival rates during the active season than females, which corresponds with the 'risky male hypothesis'. Survival rates of females appeared too low to keep populations at a stable level. To establish a viable population, more optimal environmental conditions for both survival and reproduction of the hamsters are necessary. Using electric fences around fields with hamsters significantly increased the survival of females. However, hamster conservationists need to consider not just subadult and adult survival rates, but also habitat connectivity, weather effects on reproduction, and alternative agricultural practices on a landscape scale.
\end{abstract}

Keywords Predation $\cdot$ Reintroduction $\cdot$ Reproduction $\cdot$ Rodent $\cdot$ Survival $\cdot$ Transmitter

\section{Introduction}

The Common or European hamster (Cricetus cricetus) has a range extending from Europe through Russia as far as the most western border of China (Surov et al. 2016). This medium-sized rodent originally is native to steppe habitat,

Handling editor: Emma Vitikainen.

Electronic supplementary material The online version of this article (https://doi.org/10.1007/s42991-020-00063-5) contains supplementary material, which is available to authorized users.

Maurice J. J. La Haye

Maurice.Lahaye@zoogdiervereniging.nl

1 Department of Animal Ecology and Physiology, Institute for Water and Wetland Research, Radboud University, Nijmegen, the Netherlands

2 Wageningen Environmental Research, Animal Ecology, Wageningen, the Netherlands but has successfully adapted to live in agricultural habitats, as well. For most of the twentieth century, Common hamsters have been regarded as an agricultural pest in Europe, and were hunted heavily, although irregular population outbreaks did occur (Nechay 2000). In the last 30 years, European populations have declined significantly in range and numbers (Nechay 2000; Melosik et al. 2016; Surov et al. 2016), and currently, the Common hamster is endangered in most of the European countries where it resides. It is listed in the European Habitats Directive (Council Directive 92/43/ EEC) as an iconic species of agricultural landscapes with high conservation priority (Orbicon et al. 2008).

In France, Germany, Belgium, and the Netherlands, the most western part of the distribution range of Common hamsters, population declines in the 80s triggered conservation and research projects, particularly in France and the Netherlands (Kuiters et al. 2010; Villemey et al. 2013). These projects are a combination of conservation and research to monitor and investigate whether 'hamster-friendly' 
agri-environmental schemes (AES) are an effective conservation tool, and whether AES result in viable hamster populations in the long term (Kuiters et al. 2010; La Haye et al. 2014).

Information on survival rates is a key element in conservation plans for the Common hamster (Ulbrich and Kayser 2004; La Haye et al. 2014) and essential to understand the population dynamics of this species. Accurate estimates of survival rates of Common hamsters are very scarce, as most projects studying the survival of hamsters had small sample sizes or were restricted in time (Kayser 2002; Kuiters et al. 2007; Kupfernagel 2007; Losík et al. 2007; Villemey et al. 2013). In the Netherlands, a breeding program and local reintroduction of the species were initiated in response to the national extinction of the species in 2002 (Kuiters et al. 2010). The released captive-bred hamsters and their wild-born offspring were monitored to collect information on hamster survival rates, using transmitters and recording when individuals were killed or predated (and by which predator).

In this study, we developed a Markov Chain Monte Carlo (MCMC) model to analyse survival rates of more than 800 captive-bred and wild-born Common hamsters in the Netherlands, which were followed over 15 years. Our main goal was to present detailed seasonal survival rates of wild-born and captive-bred hamsters, and to explore the main causes of death and factors influencing their survival. We expected that hamsters would be predated by a number of different predators and that survival was sufficient for viable population dynamics in fields with 'hamster-friendly' agri-environmental schemes.

\section{Materials and methods}

Common hamsters are nocturnal, solitary-living, mediumsized rodents, with adults weighing $200-500 \mathrm{~g}$ on average. The species usually hibernates underground from the end of October until the beginning of April (Nechay 2000; Schmelzer and Millesi 2008). Hamsters are polygamous, with usually $1-3 \mathrm{~L}$ per season, with a gestation period of $17-18$ days (Nechay 2000).

The present study was performed in the southernmost part of the Netherlands, in three areas of the province of Limburg: South (Amby-Heer-Sibbe; 50 50' 18' N, $5^{\circ} 48^{\prime}$ $32^{\prime \prime}$ E), Centre (Sittard-Puth-Jabeek; 50 57' 42" N, $5^{\circ} 52^{\prime}$ $45^{\prime \prime}$ E), and North (Koningsbosch; $51^{\circ} 02^{\prime} 41^{\prime \prime} \mathrm{N}, 5^{\circ} 57^{\prime} 35^{\prime \prime}$ $\mathrm{E})$, hereafter referred to as areas $\mathrm{A}, \mathrm{B}$, and $\mathrm{C}$, respectively (Fig. S1 in the Electronic Supplementary Material). The hamster can be found on arable land with loess or loamy soils, which, in the Netherlands, are restricted to this region in Limburg (Kuiters et al. 2010). The study sites are part of a typical local agricultural landscape: relatively open, with a mosaic of grassland, arable fields, small woodlands, small villages, and small roads. Fields are approximately a few hectares in size and cereals are cultivated on $15-20 \%$ of all the arable fields. Harvest of cereals starts at the beginning of July and continues till the first half of August.

In each of the study sites, adaptive 'hamster-friendly' agricultural management has been established through the implementation of 'hamster-friendly' agri-environmental schemes (AES). Hamster-friendly management on arable fields implies the cultivation of suitable crops like cereals and alfalfa, in combination with harvesting restrictions, with the goal to improve survival rates of hamsters and to provide suitable conditions for reproduction over a longer time period than on regularly managed cereal and alfalfa fields (La Haye et al. 2014).

This study was strongly biased to arable fields with 'hamster-friendly' management, arable fields with an AES, and farmland nature reserves, because almost no hamsters live on regularly managed agriculture fields anymore. Although, each year, some hamsters and a few burrows are found on regularly managed cereal fields too, hamsters rely heavily on arable fields with 'hamster-friendly' management (Kuiters et al. 2010).

\section{Transmitters}

Hamsters in the wild were trapped at the entrance of their burrow between the end of March and the end of October, although trapping was minimal in June-August to prevent damage in standing crops. Trapped hamsters were equipped with an implant radio transmitter (6-8 g, type BioWise constructed by Madebytheo in Nijmegen, the Netherlands) by a veterinarian from Burgers Zoo (Arnhem, the Netherlands). For individual identification purposes, all trapped hamsters from the wild also received a pit tag $(2 \times 12 \mathrm{~mm}$, ISO FDX B compatible transponder, ordered at www.dierchip.nl, Aalten, the Netherlands). In all cases, wild hamsters were released at their burrow within $48 \mathrm{~h}$ after trapping.

Each year, approximately $25 \%$ of the number of captivebred hamsters released into the wild were equipped with implant radiotransmitters and pit tags. The surgical operations of transmitter implantation were at least 5 days before the release in the wild, to check the individuals for complications. Released captive-bred hamsters were 1 or 2 years old, depending on whether they provided offspring in the breeding program (La Haye et al. 2017). Surgery of captivebred hamsters was done by veterinarians at Blijdorp Zoo (Rotterdam, the Netherlands) and GaiaZOO (Kerkrade, the Netherlands).

The radiotransmitters also informed us about the temperature of the hamsters, which made it possible to distinguish between living hamsters and dead or hibernating hamsters. Due to the use of a $30 \mathrm{MHz}$ frequency band, the signal was 
detectable at a distance of 150-300 m, even when hamsters were underground.

From 2002 to 2016, a total of 877 different common hamsters, wild-born and captive-bred, were equipped with a radio transmitter and followed until their death or loss of the radio signal (Table 1). Hamsters that were re-trapped after not being observed for more than 60 days (which is threeto-four times the regular monitoring interval) were treated in our analysis as new individuals. This specific treatment of re-trapped hamsters was done, because the chance of retrapping alive after 60 days is small, as most hamsters that were not recorded for such a long time were never re-trapped again and likely are dead. If this bias was not taken into account, our dataset would overestimate survival rates as only surviving re-trapped individuals would have contributed to the dataset, while that is, of course, impossible for hamsters that were not re-trapped or had died. Re-trapping hamsters after more than 60 days especially happened in early spring directly after the hibernation period. During hibernation, hamsters stay underground, which makes recapture nearly impossible.

It is not possible to exactly ascertain the age of a wild hamster, but only hamsters weighing at least $200 \mathrm{~g}$ were equipped with a transmitter. Therefore, we assumed that all trapped hamsters were at least (sub)adults.

\section{Monitoring survival}

All hamsters with a working transmitter were located once a week or once every 2 weeks during the active season, from mid-March to mid-October, and at least once in every 2 or 3 weeks during winter months (November-February). Each hamster was checked at its burrow during daylight hours. If we did not find a hamster during a regular check, we tried to locate it near the last known location as soon as possible. Most of the missing hamsters or transmitters, if missed during a regular check, were relocated within $500 \mathrm{~m}$ from the last known location (van Wijk et al. 2011) within two weeks.

If a hamster turned out to be dead during a regular check, as much information as possible was collected from the carcass and transmitter. All dead hamsters or their remains were dissected. The tracks and signs in the field and the findings during dissections were used to deduct the cause of death.
Various pieces of information were taken into consideration, from bite marks on the transmitter to the location of the transmitter. Transmitters in nests high up in a tree or directly under meadow poles with bird feces underneath were attributed to predation by birds of prey. Hamsters or transmitters in or nearby a fox den were noted as being killed by a fox (Vulpes vulpes), as well were freshly buried hamsters and loose transmitters on the field. Signs of predation by mustelids were more diverse as beech martens (Mustela foina) mostly brought hamsters inside a house or barn, while stoats (Mustela erminea) and polecats (Mustela putorius) left remains like the skin and legs in the field. Hamsters which were killed and showed subcutaneous haemorrhages, but were not eaten, were attributed to dogs (Canis lupus familiaris). Some hamsters were killed by badgers (Meles meles) as their excavated burrows showed the typical signs of badger nails. Rats and mice killed some hamsters during hibernation, most likely during a period of torpor, as their burrows showed signs of rat or mice activity at the moment the radio signal indicated that a hamster had died. Some hamsters were killed by farming activites. A handfull were suppressed in their burrow by farming vehicles or hit by a plough or harvesting machine. In other cases, hamsters were recovered close to other burrows and were thought to be killed by another hamster during territorial conflicts. Determining the cause of death was sometimes difficult, and we only assigned a kill to a specific predator or other cause of death when we were positively convinced by the sign indicated above. In 17\% ( $n=80)$ of the cases, we were not certain about the cause of death, and these cases are indicated as 'unknown' in Table 2.

\section{Electric fences and spotlight hunting of foxes}

As part of the conservation program, enclosures were made with an electric fence to protect hamsters in some areas. Enclosures were not set up as a scientific experiment. However, we recorded during each visit, whether a hamster with a transmitter was located inside or outside enclosures. These enclosures excluded foxes and other large ground-dwelling predators like badgers and dogs, but enclosures were open for aerial predators and small mustelids (Kuiters et al. 2010; Villemey et al. 2013). The number of electric-fence
Table 1 The status of all observed hamsters at the end of the observations in the period 2002 till 2016, with sex and origin taken into account

\begin{tabular}{llllll}
\hline Status & Total $(N=938)$ & $\begin{array}{l}\text { Wild- } \\
\text { born male } \\
(N=248)\end{array}$ & $\begin{array}{l}\text { Wild-born } \\
\text { female } \\
(N=276)\end{array}$ & $\begin{array}{l}\text { Captive-bred } \\
\text { male }(N=187)\end{array}$ & $\begin{array}{l}\text { Captive- } \\
\text { bred female } \\
(N=227)\end{array}$ \\
\hline Dead & $466(50 \%)$ & $119(48 \%)$ & $106(38 \%)$ & $134(72 \%)$ & $107(47 \%)$ \\
Present (alive) & $219(23 \%)$ & $32(13 \%)$ & $60(22 \%)$ & $43(23 \%)$ & $84(37 \%)$ \\
Lost & $238(25 \%)$ & $95(38 \%)$ & $97(35 \%)$ & $10(5 \%)$ & $36(16 \%)$ \\
Transmitter failure & $15(2 \%)$ & $2(1 \%)$ & $13(5 \%)$ & - & - \\
\hline
\end{tabular}


Table 2 Cause of death of 466 common hamsters in the period of 2002 till 2016 as observed in the field

\begin{tabular}{|c|c|c|c|c|c|}
\hline Cause of death & Total $(N=466)$ & $\begin{array}{l}\text { Wild-born male } \\
(N=119)\end{array}$ & $\begin{array}{l}\text { Wild-born } \\
\text { female }(N=106)\end{array}$ & $\begin{array}{l}\text { Captive-bred } \\
\text { male }(N=134)\end{array}$ & $\begin{array}{l}\text { Captive- } \\
\text { bred female } \\
(N=107)\end{array}$ \\
\hline Predation & $369(79 \%)$ & $96(81 \%)$ & $83(78 \%)$ & $108(81 \%)$ & $82(77 \%)$ \\
\hline Fox (Vulpes vulpes) & $142(30 \%)$ & $44(37 \%)$ & $22(21 \%)$ & $50(37 \%)$ & $26(24 \%)$ \\
\hline Mustelids (Mustelidae spec.) & $108(23 \%)$ & $22(18 \%)$ & $24(23 \%)$ & $27(20 \%)$ & $35(33 \%)$ \\
\hline Birds of prey (Buteo buteo, Falco tunninculus) & $91(20 \%)$ & $25(21 \%)$ & $36(34 \%)$ & $15(11 \%)$ & $15(14 \%)$ \\
\hline Dog (Canis lupus familiaris) & $16(3 \%)$ & $2(2 \%)$ & $1(1 \%)$ & $9(7 \%)$ & $4(4 \%)$ \\
\hline Badger (Meles meles) & $7(2 \%)$ & $2(2 \%)$ & - & $3(2 \%)$ & $2(2 \%)$ \\
\hline Mouse/rat (Muridae spec.) & $5(1 \%)$ & $1(1 \%)$ & - & $4(3 \%)$ & - \\
\hline Other & $97(21 \%)$ & $23(19 \%)$ & $23(22 \%)$ & $26(19 \%)$ & $25(23 \%)$ \\
\hline Unknown & $80(17 \%)$ & $18(15 \%)$ & $19(18 \%)$ & $20(15 \%)$ & $23(21 \%)$ \\
\hline Farming activity & $8(2 \%)$ & $3(3 \%)$ & $3(3 \%)$ & $1(1 \%)$ & $1(1 \%)$ \\
\hline Common hamster (Cricetus cricetus) & $9(2 \%)$ & $2(2 \%)$ & $1(1 \%)$ & $5(4 \%)$ & $1(1 \%)$ \\
\hline
\end{tabular}

Predation was the main reason for mortality, with foxes as the main predator being responsible for $30 \%$ of all mortalities

enclosures ranged from one to four per year (with a mean of two), and enclosures were randomly distributed over all areas. On average, these enclosures protected an area of twoto-three hectares.

Regular daylight hunting of foxes was allowed in all years in all areas, but additional spotlight hunting during the nightly hours, after sunset and before sunrise, was only allowed with a special permit. The intensity of additional spotlight hunting, therefore, varied between years and areas (see Table S1 in the Electronic Supplementary Material).

\section{Survival model}

Survival rates, expressed as survival over 1 week, were estimated as a function of multiple variables. We first tested whether males had different survival rates than females during the active season (see below) with a model that also included the day of the year and the site where a hamster lived (A, B, or C). We then decided to fit sex-specific models with day number, site, as well as the following factors: whether a hamster was wild-born or captive-bred, presence of an electric fence, and an adaptive period for captive-bred hamsters after release (explained below). Each record in the dataset (La Haye et al. 2020) represented an exposure interval $(j)$ between two subsequent observations in time for each specific hamster, with a binary outcome $S j \in[0,1]$ (dead or alive at the end of the interval) over an exposure interval of $t(j)$ days (across all observations, exposure intervals were on average 9 days long, with 50\% of intervals lasting 6-12 days). An appropriate model for binary outcomes of survival is logistic regression. However, our data do not represent identically replicated binary trials, because the outcomes (alive or dead at the end of an interval) depend on interval exposure length, with longer exposure time negatively affecting outcome probabilities. We, therefore, adopted a survival model akin to Shaffer (2004), in which survival is modeled by the aid of logistic regression with a link function that acknowledges the effect of variable exposure length between the intervals:

$S(j)=p^{t(j)}=\left[\frac{1}{\exp \left(-\alpha-\sum_{i} \beta i X i j\right)}\right]^{t(j)}$,

where $p$ is the weekly survival rate, $t$ the exposure length (expressed in weeks) of interval $j, \alpha$ a global intercept, $X i j$ the covariates, and $\beta i$ the corresponding coefficients. This model does not make any assumptions on when precisely individuals died during the exposure interval, but does, however, assume that the survival rate is constant within intervals.

In this model, weekly survival was expressed as an additive function of location and a third-order polynoom of day number. Additionally, we included an adaptation variable to test whether newly released captive-bred hamsters had a different survival rate than hamsters not introduced from captivity. A released hamster's adaptation effect was allowed to linearly diminish from 1 to 0 in a to-be-estimated number of days since its release, after which survival was assumed to be equal to that of hamsters that were not recently released from captivity. In the active season, in our region between mid-March and midOctober, we also included additive effects of the presence of enclosures (plots with an electric fence). In all models, we allowed survival to vary between years.

The effect of additional hunting of foxes with spotlights was left out of the above models, because additional 
spotlight hunting did not occur before 2009 and was allowed in all sites in the last 2 years. We, therefore, fitted additional (sex-specific) models that included additional spotlight hunting (locally allowed or not) as a factor during the active season, based on data for a subset of years (2009-2014).

Estimates of parameters were obtained using MCMC algorithms facilitated by the R2jags package in $\mathrm{R}$ ( $\mathrm{Su}$ and Yajima 2015). Vague priors were used for all estimated parameters, and 12,000 iterations were run in each of three chains with a burn-in of 2000 and a thinning rate of 10 . The continuous explanatory variable day number was scaled to mean zero and unit variance before subsetting the dataset for the sex-specific analyses. The significance of the parameter estimates was based on the proportion of the posterior values with an opposite sign (negative or positive) from that of the mean. The significance of the difference between the parameter estimates between the female and male models was tested by comparing the posterior values pairwise and quantifying the proportion of cases where the sign of the difference was opposing that of the difference in the means.

\section{Results}

Our dataset consists of 877 individuals of which 818 individuals were followed continuously until their death, 57 individuals were re-trapped alive and refitted with a transmitter after being missed during at least 60 days and two individuals were even re-trapped alive after a being missed for a second period of 60 days. These efforts resulted in 938 time-series of monitored hamsters in the years 2002-2016. In total, these 938 time-series consisted of 9083 monitoring intervals, with a monitoring interval being the period between monitoring events to locate transmitters or, in case of a missing transmitter/hamster, up to the day on which an extensive survey was done to relocate the lost transmitter and/or dead hamster. These 9083 monitoring intervals have been used as input for our survival models.

At the end of our 938 time-series, 466 hamsters (50\%) were found dead, 219 hamsters (23\%) were known to be alive, 238 hamsters (25\%) disappeared without knowing the fate of the hamster, and 15 hamsters had a failing transmitter (2\%). An overview is presented in Table 1. In this table, we also show that captive-bred hamsters were more likely to be recovered than wild-born hamsters: almost one-third of wild hamsters were eventually lost without any sign, while approximately $10 \%$ of captive-bred hamsters were lost without knowing their fate $\left(\chi^{2}=83.1, p<0.001\right)$. This difference is most likely related to the lifespan of the battery of the transmitter (3-6 months), which is shorter than the expected lifetime of a wild hamster, while the opposite is true for captive-bred hamsters.
The majority of hamsters that died in our study $(n=466)$ were killed by foxes, mustelids, and birds of prey, which were responsible for at least $73 \%(n=341)$ of all known mortalities (Table 2). Male hamsters, wild-born and captivebred, were more often killed by foxes than females. Birds of prey were the most important predator of wild females. It is important to highlight that the location where a dead hamster or the transmitter was found is not necessarily the location where a hamster was caught by a predator. This is especially crucial when assessing the mortality risks of hamsters that were located alive within an enclosure, but found dead outside the enclosure in the next session.

\section{Survival rates, seasonality, and site effects}

The initial model showed that in the active season, males have a lower survival rate than females: the effect size of the factor 'male' in the logistic regression was -0.63 (standard deviation $=0.11,95 \%$ confidence interval $=-0.84 /-0.43$, significance level $=0.000$ ). This sex difference is also seen in the predictions of the sex-specific models (Fig. 1, Table S3). Outside the active season, weekly survival was more similar between males and females. Within the active season, the lowest survival in males is registered in June, while females show the lowest survival rates in May-July, but overall females clearly have higher survival rates than males during the active season (Table S2). In some years, female survival rates significantly differed from their overall mean (Fig. 2, Table S3). Note that, until 2010, these year effects were mainly positive, while female survival rates since 2011

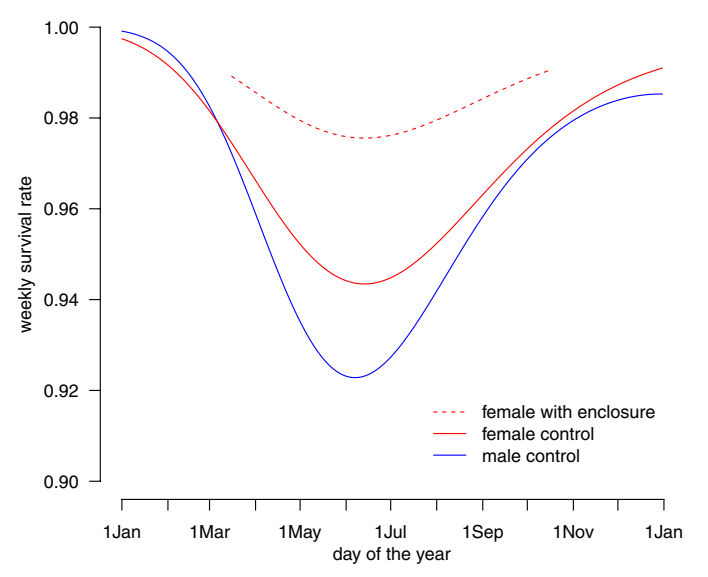

Fig. 1 Weekly survival rates of female and male hamsters (continuous lines; significantly different in the active season) and survival rates of females when protected by an electric fence (interrupted line). An electric fence around a plot had a significant positive effect on the survival rates of females during the active season, but not on survival rates of males (not shown to retain focus on significant effects). Model predictions are shown for wild hamsters in an average site and year, and ignore potential effects for newly released hamsters or spotlight hunting. Please note that the $y$-axis (weekly survival) ranges from 0.9 to 1 

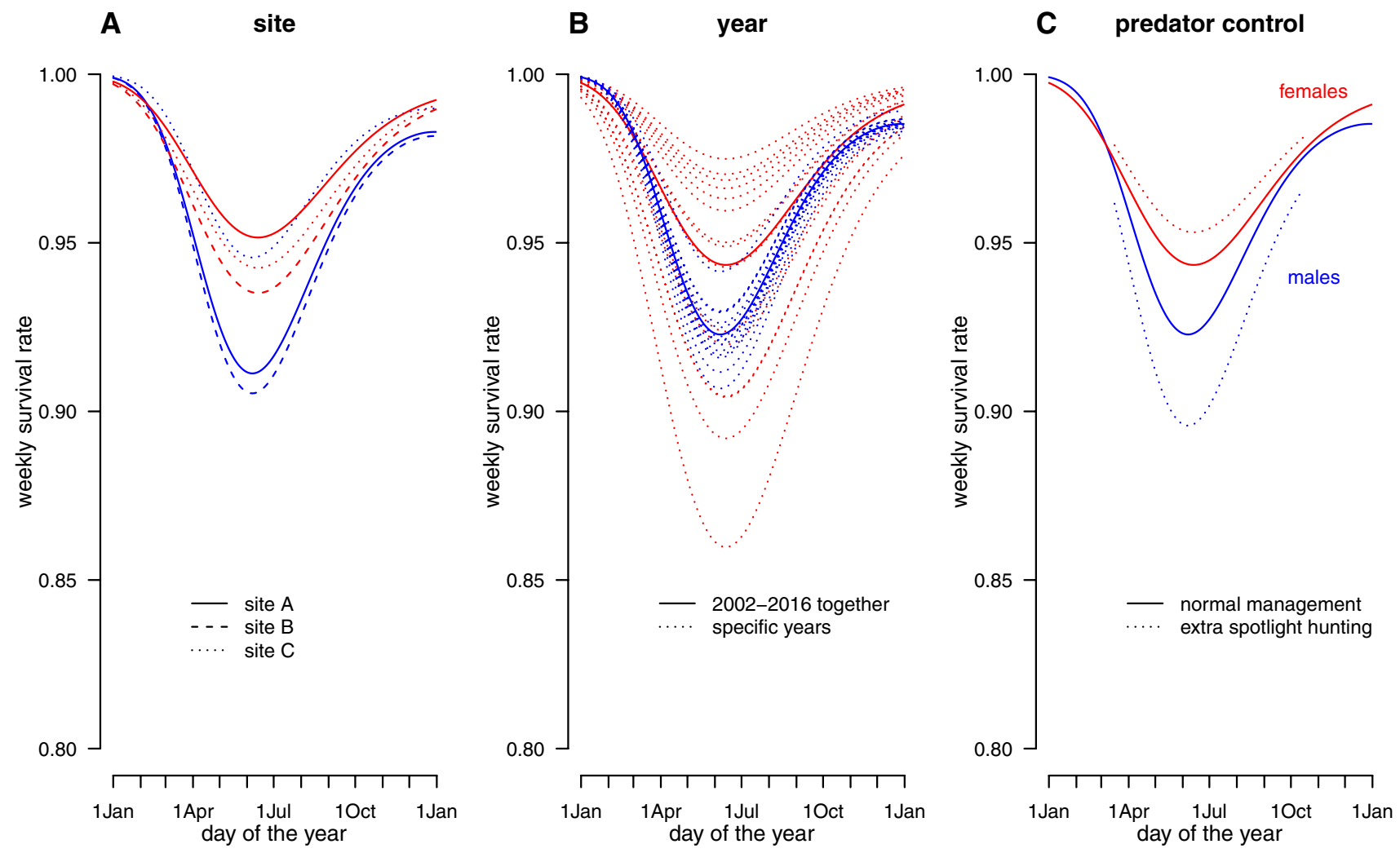

Fig. 2 Weekly survival rates of female (red) and male (blue) hamsters in the Netherlands, illustrating the modeled effect sizes listed in the Appendix S3. As explained in the Materials and methods section, separate models were fitted to data on female and male hamsters. a Site-specific survival rates are shown for females and males. b Year effects vary more for females than for males. c Additional predator

were mainly below average. Survival rates in males did not significantly differ from their overall mean in any of the years (Table S3).

For males, the site-specific intercepts were significantly $(p<0.05)$ lower for sites A and B than for site C, resulting in the prediction of annual survival of wild males outside enclosures of $9.7 \%$ (site A), $8.0 \%$ (B), and $24.6 \%$ (C). For females, site intercepts differed only significantly between sites $\mathrm{A}$ and $\mathrm{B}$, resulting in annual survival rates of $25.1 \%$, $15.2 \%$, and $19.2 \%$ for sites $\mathrm{A}, \mathrm{B}$, and $\mathrm{C}$, respectively.

\section{Adaptive period in released captive-bred hamsters}

Survival of captive-bred hamsters is much lower than that of wild-born hamsters in the period following their release in the wild, but survival rates increased in the subsequent weeks after release (Fig. 3). Surviving captive-bred females had survival rates comparable to those of wild females 19 days after their release, while it took 28 days for released captive-bred males to have similar survival rates as wild males. However, the difference in adaptation periods control in the form of spotlight hunting on foxes did not have a significant effect on female or male survival during the active season. The effect of spotlight hunting was evaluated in separate analyses using a subset of years (2009-2014) in which both normal management occurred as well as extra spotlight hunting

between the sexes is not statistically significant $(p=0.161)$, mainly due to the large variation in the estimate for females.

\section{Enclosures and spotlight hunting of foxes}

Hamsters were registered within an enclosure with an electric fence during 1068 observations (12\%), see table S1. An enclosure had a significantly $(p<0.001)$ positive effect on survival rates of females, but no effect on survival rates was seen for males (Fig. 1, Table S3).

Spotlight hunting was intensified in the last 4 years of the project and 1868 monitoring intervals $(21 \%)$ were collected in years and areas with spotlight hunting. Additional use of spotlight hunting had no significant effect on the survival of hamsters (Fig. 2; effect size in logistic regressions: for females 0.20 [sd $=0.43,95 \% \mathrm{CI}=-0.63 / 1.01, p=0.319$ ] and for males $-0.30[\mathrm{sd}=0.62,95 \% \mathrm{CI}=-1.39 / 1.07$, $p=0.295]$ ). 


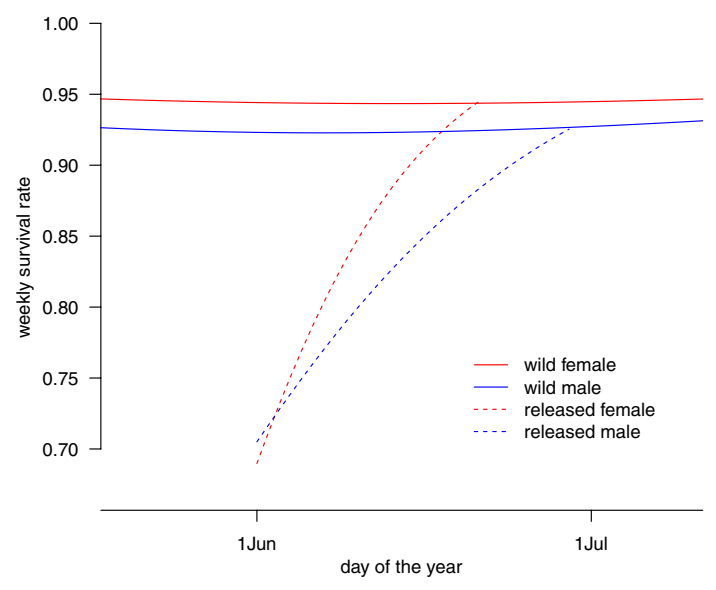

Fig. 3 Adaptive period of newly released hamsters based on their weekly survival rates. Surviving females reach the survival rate of wild females after 20.11 days, released males that of wild males after 28.48 days. The plotted effects are based on the fitted model and shown without effects of other explanatory variables like enclosures or spotlight hunting. As an example, we here show the model predictions for hamsters released on the first of June, while, in reality hamsters, captive-bred hamsters were released at various times throughout the season. As models were fit separately for males and females, the similar weekly survival rates at the time of release are based on independently estimated effect sizes for each sex

\section{Discussion}

Predation is by far the most important cause of mortality in wild-born and captive-bred hamsters and at least $73 \%$ of all monitored hamsters were killed by foxes, mustelids, or birds of prey (Table 1). Direct farming activities only ended the lives of eight hamsters (2\%) by compressing their shallow burrow or during ploughing (Table 2). This finding is in line with the other studies, showing that most documented deaths of common hamsters are caused by predation by a diverse set of predators (Kayser et al. 2003; Losík et al. 2007; Bihari et al. 2008; Villemey et al. 2013).

Farming activities play an important, but indirect, role in the survival of individual hamsters (La Haye et al. 2014). While, in most cases, the primary cause of mortality is a predator, it is the management of crops that determines the predation risk. Harvesting crops result in more mortalities as it reduces cover and exposes hamsters to predators (Ulbrich and Kayser 2004; Villemey et al. 2013). A similar situation can be seen in early spring when hamsters wake up from hibernation on an arable field without cover, which is the case when cereal fields are followed by sugar beets or potatoes in the next year as part of the rotation scheme of a farmer (Müskens et al. 2005). Such hamsters run a high risk of predation by foxes, birds of prey, or martens, again mainly due to a lack of cover. Survival rates can also be influenced by more cryptic factors like accumulation of pesticides or limited food resources resulting in a poor condition and, therefore, an increased risk of becoming predated. These factors are difficult to study, as at our sites most hamsters lived in fields with hamster-friendly management where the use of pesticides was minimal or not allowed, and where providing enough food for a winter storage was an important conservation goal. Besides, most hamsters that were found dead and suitable for dissection afterward were in a good condition, so we do not think that starvation influenced survival rates too much. In our study, we not only focused on identifying the most important predators, but also presented detailed survival rates of wild-born and captive-bred hamsters and explored the effect of some predator control measures like the use of electric fences and spotlight hunting of foxes.

\section{Survival rates of captive-bred and wild hamsters}

We found a significant difference in survival between released captive-bred and wild-born hamsters, at least in the first weeks after releasing captive-bred individuals in the wild. It is well known that animals raised in captivity and used for reintroduction do not have the skills needed to survive in the wild (Aaltonen et al. 2009; Jule et al. 2008). Survival of captive-bred individuals can, therefore, be very low in the first phase of a reintroduction as a result of inappropriate behaviour (Stoinski et al. 2003) or stress (Teixeira et al. 2007). In the first week, one out of four released hamsters died according to the fitted model. However, released individuals rapidly adapt to the wild and the individuals that survived the first 19 days (for females) and 28 days (for males) reached similar subsequent survival rates as hamsters that were not recently released from captivity. It is unclear whether all captive-bred individuals have the same survival probability in the first weeks after their release, or whether some form of selection took place. In either case, this 'adaptation period' comes at the expense of high losses, which may have demographic and genetic consequences (La Haye et al. 2017). The hamster populations in western Europe already have an impoverished genetic diversity (La Haye et al. 2012a) and a further decline in genetic diversity may affect population persistence in the long term as a lowered genetic diversity is associated with endangered and strongly declining populations (Madsen et al. 1999; Westemeier et al. 1998; Carlson et al. 2014; Whiteley et al. 2015). The hamster breeding program has, therefore, implemented a breeding strategy of minimizing kinship (La Haye et al. 2012b) to release genetically diverse hamsters. However, habitat quality and habitat management often play more dominant roles in population persistence (Spielman et al. 2004; Bouzat et al. 
2009; La Haye et al. 2014). Still, it is worth testing if a pre-release training of captive-bred hamsters can have a positive effect on the survival of released hamsters (Fleitz et al. 2018). This may increase the success of a reintroduction, but is also important from an animal welfare point of view.

\section{Differences between males and females}

Male and female hamsters showed similar survival rates in the non-active period, but divergent survival rates in the active period (Fig. 1). Males had significantly lower survival rates compared to females in the active season, which is a well-known pattern in rodents and which has been documented for several other rodents like Mongolian gerbils (Liu et al. 2009) or Bank voles (Crespin et al. 2002). Lower survival rates in male hamsters compared to females correlate with more frequent movements between burrows and longer movements of males between burrows compared to females (van Wijk et al. 2011). A behaviour is consistent with the 'risky male behaviour' hypothesis (Norrdahl and Korpimäki 1998; Kraus et al. 2008). Males are actively looking for receptive females, which probably influences their condition and/or their behaviour, making them more vulnerable for predation. In contrast, female hamsters stay longer on their burrow and only move to another burrow after weaning their litter or after agricultural activities like harvest when cover is reduced (Müskens et al. 2005; van Wijk et al. 2011). Female hamsters also have smaller home ranges (Weinhold 1998; Müskens et al. 2005), which may also lower predation risk as it can be expected that females are close to the safety of their burrow at all times.

In the first years of our study, until 2010, survival rates of females were mostly above average, while survival rates since 2011 were mainly quite low. An explanation for this negative trend in female survival rates is lacking, but clearly has a negative effect on population persistence. Perhaps, lower survival in later years was a result of unfavorable weather conditions during consecutive summers. Surprisingly, survival rates of male hamsters did not significantly differ from the overall mean during any of the years (Table S3), suggesting that males have low survival rates under all conditions.

The timing of harvest of cereals is identified as an important parameter for the survival of hamsters (La Haye et al. 2010) as it has a strong effect on reproductive output and sustainability of a population (La Haye et al. 2014), but no clear change was apparent in the timing of cereal harvesting activities since 2011. The low survival rates of females since 2011 imply that hamster populations in later years were more vulnerable than in earlier years. Besides, although survival rates of males did not differ between years, all hamster populations actually had low proportions of males (La Haye et al. 2010). It is possible that a low density of males has a negative or delaying effect on reproduction in some years (La Haye et al. 2017). Too few males could result in a delayed reproduction in spring or even result in non-fertilized females during the reproductive period.

\section{Effect of electric fencing and spotlight hunting}

A protection measure that was implemented to increase the survival of hamsters was putting up electric fences around plots where captive-bred hamsters were released or around plots with burrows of wild-born hamsters. An electric fence excludes foxes (La Haye et al. 2008; Villemey et al. 2013) and other large ground-dwelling predators like badgers and dogs, although it is open for aerial predators and small mustelids. Our analyses tested if an electric fence results in a better survival for hamsters located in an enclosure at the beginning of a time interval, which appeared to be true in females. An electric fence around a small plot significantly results in higher survival rates of female hamsters (Fig. 1), but no effect on survival rates of males was found. This is probably because males had a daily and periodic area of activity which exceeded the fenced plots, while females likely stayed within the relative safety of the enclosure (van Wijk et al. 2011).

The main predator of hamsters were foxes (Table 2), which was an important argument for the responsible authorities to allow extra hunting on foxes with spotlights in the nightly hours in the period 2009-2014. However, the evidence that an intensified shooting of foxes results in reduced population or a lower density is at least questionable (Baker and Harris 2006; Beja et al. 2009), and intensified hunting is unlikely to have a positive effect on the survival of the species of conservation concern (Summers et al. 2004). A comparison of survival rates of monitoring intervals with and without spotlight hunting in the same years, which was only possible for a subset of the dataset, did not result in increased survival rates of hamsters in areas with spotlight hunting, confirming the low effectivity of hunting foxes to increase survival rates of hamsters.

\section{Increasing the success of conservation projects}

La Haye et al. (2014) used a population model to conclude that female hamsters needed at least two litters per season for a sustainable population and that agri-environmental schemes (AES) should be optimized to promote a better survival of female hamsters by delaying the time of harvest. La Haye et al. (2014) used yearly survival rates of $30 \%$ for adult females, but our results show a considerably lower mean annual survival rate of just $20 \%$ for females, 
strongly suggesting that mean survival rates are too low for a sustainable population, even on fields with AES. Only in some years did the survival rates exceed the threshold of $30 \%$ (Fig. 2), indicating that environmental conditions are sometimes more optimal for hamsters than in other years (Hufnagl et al. 2011). Further research will have to show whether occasional years favorable for survival and reproduction are sufficient to maintain long-term population viability. It is attractive to link years with a better survival to a late harvest or crops with more cover, but direct measurements of the timing of harvest are missing. Identifying optimal management (e.g., delayed or advanced harvest of cereals) is complex and probably includes multiple factors like weather conditions, choice of crops, and EU farming regulations (Kuiters et al. 2010; Müskens and La Haye 2012; Surov et al. 2016; Tissier et al. 2016).

Hence, low mean survival makes population persistence for hamsters difficult and is a major challenge for conservation projects of this species. Increasing the survival rate of hamsters is essential, but solutions are difficult to implement. It is clear that short-term measures like electric fences can boost populations of hamsters in small areas, but this is not a long-term or large-scale solution. A comparable problem of low survival rates and a low reproductive success of endangered species are also visible in farmland and meadow birds (Laidlaw et al. 2017; Mason et al. 2018). The problem of low survival rates and low reproductive success of all kind of threatened farmland species seems to be linked with unfavorable landscape features, intensive agriculture practices, a changing climate (Surov et al. 2016; Tissier et al. 2016), and problematic or insufficient EU regulations in relation to AES (Orbicon et al. 2008; Müskens and La Haye 2012; Pe'er et al. 2014). This suggests that hamster conservationists urgently need to broaden their scope and need to find other and better ways of 'hamster-friendly' agricultural management.

\section{Conclusion}

Hamsters are predated by a wide range of predators with foxes, mustelids, and birds of prey being the main predators. Captive-bred hamsters showed a lowered survival rate after release in the wild, but reached similar survival rates as their wild-born counterparts after several weeks. Male common hamsters had much lower survival rates during the active season compared to females, which corresponds to the 'risky male hypothesis'.

Increasing survival rates of hamsters are necessary for long-term population persistence and to increase the success of conservation and reintroduction projects of common hamsters. The dataset presented here provides opportunities for future modeling studies to explore what conservation activity is needed to prevent the decline of reintroduced hamster populations. No simple solution for the conservation of common hamsters has yet been identified. Some shortterm successes have been reported (Kuiters et al. 2010; La Haye et al. 2010), and our knowledge of the species has significantly increased, but success in the long-term is challenging and probably requires radical changes in agricultural management at an international level (Pe'er et al. 2014).

Acknowledgements We thank Rotterdam Zoo, Stichting Das \& Boom, and GaiaZOO for their cooperation and breeding efforts. Loek Kuiters and Hans Peter Koelewijn gave useful feedback on earlier versions of the manuscript.

Funding This research project was funded by the Dutch Ministry of Agriculture, Nature and Food Quality (Program BO-02-013: Active policy on species management).

Code availability All analyses were performed in R, and analysis code can be found in the Electronic Supplementary Material.

\section{Complaince with ethical standards}

Conflict of interest The authors declare that there is no conflict of interests nor competing interests.

Ethics approval Trapping and surgery were done under permission of the Dutch Fauna \& Flora Act (license numbers FF/75A/2005/012 and FF/75A/2009/031) and according to the Dutch Animal Welfare Act (protocol number ALT05.03 and follow-ups). Surgery and implantation procedures of transmitters were almost similar as described in Capber (2011). Within more than 500 trapping and over 800 operation events, only two fatal accidents as a direct result of trapping and implanting a transmitter were reported. One wild hamster died during surgery because of heart failure, while the second wild hamster was found dead in the field with an open suture.

Availability of data and material Raw data are available in data repository DANS: https://doi.org/10.17026/dans-zmh-h9ah.

Open Access This article is licensed under a Creative Commons Attribution 4.0 International License, which permits use, sharing, adaptation, distribution and reproduction in any medium or format, as long as you give appropriate credit to the original author(s) and the source, provide a link to the Creative Commons licence, and indicate if changes were made. The images or other third party material in this article are included in the article's Creative Commons licence, unless indicated otherwise in a credit line to the material. If material is not included in the article's Creative Commons licence and your intended use is not permitted by statutory regulation or exceeds the permitted use, you will need to obtain permission directly from the copyright holder. To view a copy of this licence, visit http://creativecommons.org/licenses/by/4.0/.

\section{References}

Aaltonen K, Bryant AA, Hostetler JA, Oli MK (2009) Reintroducing endangered Vancouver Island marmots: survival and cause-specific mortality rates of captive-born versus wild-born individuals. 
Biol Conserv 142:2181-2190. https://doi.org/10.1016/j.bioco n.2009.04.019

Baker PJ, Harris S (2006) Does culling reduce fox (Vulpes vulpes) density in commercial forests in Wales, UK? Eur J Wildlife Rescue 52:99-108. https://doi.org/10.1007/s10344-005-0018-y

Beja P, Gordinho L, Reino L, Loureiro F, Santos-Reis M, Borralho R (2009) Predator abundance in relation to small game management in southern Portugal: conservation implications. Eur J Wildl Res 55:227-238. https://doi.org/10.1007/s10344-008-0236-1

Bihari Z, Horváth M, Lanszki J, Heltai M (2008) Role of the Common Hamster (Cricetus cricetus) in the diet of natural predators in Hungary. In: Biosystematics and ecology series no. 25. Austrian Academy of Sciences Press, Vienna

Bouzat JL, Johnson JA, Toepfer JE, Simpson SA, Esker TL, Westemeier RL (2009) Beyond the beneficial effects of translocations as an effective tool for the genetic restoration of isolated populations. Conserv Genet 10:191-201. https://doi.org/10.1007/s1059 2-008-9547-8

Capber F (2011) Intra-peritoneal radio-transmitters implants in European hamsters (Cricetus cricetus). In: Proceedings of the 18th meeting of the international hamster workgroup, Strasbourg, pp 29-32

Carlson SM, Cunningham CJ, Westley PAH (2014) Evolutionary rescue in a changing world. Trends Ecol Evol 29:521-530. https:// doi.org/10.1016/j.tree.2014.06.005

Crespin L, Verhagen R, Stenseth NC, Yoccoz NG, Prévot-Julliard A-C, Lebreton J-D (2002) Survival in fluctuating bank vole populations: seasonal and yearly variations. Oikos 98:467-479. https:// doi.org/10.1034/j.1600-0706.2002.980311.x

Fleitz J, Enstipp M, Parentx E, Jumeau J, Handrich Y (2018) Improving the success of restocking programs: effects of a pre-release training period on the anti-predator behaviour of common hamsters. In: Abstract book 25th meeting of the international Hamster workgroup, Strasbourg

Hufnagl S, Franceschini-Zink C, Millesi E (2011) Seasonal constraints and reproductive performance in female Common hamsters (Cricetus cricetus). Mamm Biol 76:124-128. https://doi. org/10.1016/j.mambio.2010.07.004

Jule KR, Leaver LA, Lea SEG (2008) The effects of captive experience on reintroduction survival in carnivores: A review and analysis. Biol Conserv 141:355-363. https://doi.org/10.1016/j. biocon.2007.11.007

Kayser A (2002) Populationsökologische Studien zum Feldhamster Cricetus cricetus (L., 1758) in Sachsen-Anhalt. Dissertation, Martin-Luther-Universität Halle-Wittenberg

Kayser A, Weinhold U, Stubbe M (2003) Mortality factors of the common hamster Cricetus cricetus at two sites in Germany. Acta Theriol 48:47-57. https://doi.org/10.1007/BF03194265

Kraus C, Eberle M, Kappeler PM (2008) The costs of risky male behaviour: sex differences in seasonal survival in a small sexually monomorphic primate. Proc R Soc B 275:1635-1644. https ://doi.org/10.1098/rspb.2008.0200

Kuiters AT, La Haye MJJ, Müskens GJDM, van Kats RJM (2007) Survival analysis to predict the predation risk in reintroduced populations of the common Hamster (Cricetus cricetus) in the Netherlands. In: V European congress of mammalogy, Siena. Hystrix It J Mamm Supp 112

Kuiters L, La Haye M, Müskens G, van Kats R (2010) Perspectieven voor een duurzame bescherming van de hamster in Nederland. Rapport Alterra, Wageningen

Kupfernagel C (2007) Populationsdynamik und Habitatnutzung des Feldhamsters (Cricetus cricetus) in Südost-Niedersachsen. Dissertation, Technischen Universität Carolo-Wilhelmina zu Braunschweig
La Haye M, Müskens G, van Kats R, Kuiters L (2008) Is de Hamster gebaat bij bejaging van de Vos? Levende Natuur 109:187-191 (in Dutch with an English summary)

La Haye MJJ, Müskens GJDM, van Kats RJM, Kuiters AT, Siepel $\mathrm{H}$ (2010) Agri-environmental schemes for the common hamster (Cricetus cricetus). Why is the Dutch project successful? Asp Appl Biol 100:117-124

La Haye MJJ, Koelewijn HP, Siepel H, Verwimp N, Windig J (2012a) Genetic rescue and the increase of litter size in the recovery breeding program of the common hamster (Cricetus cricetus) in the Netherlands. Relatedness, inbreeding and heritability of litter size in a breeding program of an endangered rodent. Hereditas 149:207-216. https://doi.org/10.1111/j.1601-5223.2012.02277.x

La Haye MJJ, Neumann K, Koelewijn HP (2012b) Strong decline of gene diversity in local populations of the highly endangered Common hamster (Cricetus cricetus) in the western part of its European range. Conserv Genet 13:311-322. https://doi.org/10.1007/ s10592-011-0278-x

La Haye MJJ, Swinnen KRR, Kuiters AT, Leirs H, Siepel H (2014) Modeling population dynamics of the common hamster (Cricetus cricetus): timing of harvest as a critical aspect in the conservation of a highly endangered rodent. Biol Conserv 180:53-61. https:// doi.org/10.1016/j.biocon.2014.09.035

La Haye MJJ, Reiners TE, Raedts R, Verbist V, Koelewijn HP (2017) Genetic monitoring to evaluate reintroduction attempts of a highly endangered rodent. Conserv Genet 18:877-892. https:// doi.org/10.1007/s10592-017-0940-z

La Haye MJJ, van Kats RJM, Müskens GJDM, Hallmann CA, Jongejans E (2020) Data from: predation and survival in reintroduced populations of the Common hamster Cricetus cricetus in the Netherlands. DANS 5:10

Laidlaw RA, Smart J, Smart MA, Gill JA (2017) Scenarios of habitat management options to reduce predator impacts on nesting waders. J Appl Ecol 54:1219-1229. https://doi. org/10.1111/1365-2664.12838

Liu W, Wang G, Wang Y, Zhong W, Wan X (2009) Population ecology of wild Mongolian Gerbils Meriones unguiculatus. J Mamm 90:832-840. https://doi.org/10.1644/08-MAMM-A-265.1

Losík J, Lisická L, Hríbková J, Tkadlec E (2007) Demografická struktura a procesy v prrírodní populaci křečka polního (Cricetus cricetus) na Olomoucku. Demographic structure and processes in a natural population of the common Hamster (Cricetus cricetus) in the Olomouc region (Czech Republic). Lynx 38:21-29

Madsen T, Shine R, Olsson M et al (1999) Conservation biologyrestoration of an inbred adder population. Nature 402:34-35. https://doi.org/10.1038/46941

Mason LR, Smart J, Drewitt AL (2018) Tracking day and night provides insights into the relative importance of different wader chick predators. Ibis 160:71-88. https://doi.org/10.1111/ ibi. 12523

Melosik I, Ziomek J, Winnicka K, Eichert U (2016) Genetic diversity and extinction risk in a small, declining Polish common hamster (Cricetus cricetus) population. Mamm Biol 81:612-622. https:// doi.org/10.1016/j.mambio.2016.07.044

Müskens G, La Haye M (2012) How (inter)national regulations negatively affect hamster-friendly management. In: Proceedings of the 10th meeting of the international Hamster workgroup, Tongeren

Müskens GJDM, La Haye M, van Kats RJM (2005) Reestablishment of a viable network-population of the common hamster in south-Limburg, the Netherlands: impact of crop-management and survival strips on burrow density in the release sites. Preliminary results. In: Proceedings of the 12th international Hamster congress. October, 2004. Strasbourg

Nechay G (2000) Status of Hamsters: Cricetus cricetus, Cricetus migratorius, Mesocricetus newtoni and other hamster species in Europe. In: Convention of the conservation of European wildlife 
and natural habitats Nature and Environment Series, No. 106. Council of Europe, Strasbourg, p 66

Norrdahl K, Korpimäki E (1998) Does mobility or sex of voles affect risk of predation by Mammalian predators? Ecology 79:226-232. https://doi.org/10.1890/0012-9658(1998)079[0226:DMOSO V]2.0.CO;2

Orbicon, Écosphère, ATECMA, Ecosystems LTD (2008) Species report Cricetus cricetus. Wildlife and sustainable farming and the Birds and Habitats Directives. Wildlife and Sustainable Farming Initiative, Brussels

Pe'er G, Dicks LV, Visconti P et al (2014) EU agricultural reform fails on biodiversity. Science 344:1090-1092. https://doi.org/10.1126/ science. 1253425

Schmelzer E, Millesi E (2008) Activity patterns in a population of European hamsters (Cricetus cricetus) in an urban environment. In: Proceedings of the 11 th, 14 th, 15 th meeting of the international Hamster workgroup; Budapest, Hungary (2003), Munsterschwarzach, Germany (2006) and Kerkrade, the Netherlands (2007). Wageningen/Nijmegen, the Netherlands. Part I, pp 19-22

Shaffer TL (2004) A unified approach to analyzing nest success. Auk 121:526-540. https://doi.org/10.1093/auk/121.2.526

Spielman D, Brook BW, Frankham R (2004) Most species are not driven to extinction before genetic factors impact them. Proc Natl Acad Sci USA 101:15261-15264. https://doi.org/10.1073/ pnas.0403809101

Stoinski TS, Beck BB, Bloomsmith MA, Maple TL (2003) A behavioral comparison of captive-born, reintroduced Golden Lion Tamarins and their wild-born offspring. Behaviour 140:137-160. https ://www.jstor.org/stable/4536018

Su Y-S, Yajima M (2015) R2jags: using R to Run 'JAGS'. https:// CRAN.R-project.org/package $=$ R2jags

Summers RW, Green RE, Proctor R, Dugan D, Lambie D, Moncrieff R, Moss R, Baines D (2004) An experimental study of the effects of predation on the breeding productivity of capercaillie and black grouse. J Appl Ecol 41:513-525. https://doi.org/10.11 11/j.0021-8901.2004.00891.x

Surov A, Banaszek A, Bogomolov P, Feoktistova N, Monecke S (2016) Dramatic global decrease in the range and reproduction rate of the European hamster Cricetus cricetus. Endang Species Res 31:119-145. https://doi.org/10.3354/esr00749

Teixeira CP, Schetini de Azevedo C, Mendl M, Cipreste CF, Young RJ (2007) Revisiting translocation and reintroduction programmes: the importance of considering stress. Anim Behav 73:1-13. https ://doi.org/10.1016/j.anbehav.2006.06.002

Tissier ML, Handrich Y, Robin J-P, Weitten M, Pevet P, Kourkgy C, Habold C (2016) How maize monoculture and increasing winter rainfall have brought the hibernating European hamster to the verge of extinction. Sci Rep 6:25531. https://doi.org/10.1038/ srep25531

Ulbrich K, Kayser A (2004) A risk analysis for the common Hamster (Cricetus cricetus). Biol Conserv 117:263-270. https://doi. org/10.1016/j.biocon.2003.12.006

van Wijk R, La Haye MJJ, van Kats RJM, Müskens GJDM (2011) Movement characteristics of the common hamster (Cricetus cricetus) in Limburg, the Netherlands. Säugetierkundliche Informationen Band 8, Heft 42, pp 79-92. Proceedings of the 16th and 17th meeting of the international Hamster Workgroup, Ranis, Germany (2009), Gödöllö, Hungary

Villemey A, Besnard A, Grandadam J, Eidenschenck J (2013) Testing restocking methods for an endangered species: effects of predator exclusion and vegetation cover on common hamster (Cricetus cricetus) survival and reproduction. Biol Conserv 158:147-154. https://doi.org/10.1016/j.biocon.2012.08.007

Weinhold U (1998) Zur Verbreitung und Ökologie des Feldhamsters (Cricetus cricetus L. 1758) in Baden-Württemberg, unter besonderer Berücksichtigung der räumlichen Organisation auf intensiv genutzten landwirtschaftlichen Flächen im Raum MannheimHeidelberg. Dissertation, Ruprecht-Karls-Universität Heidelberg

Westemeier RL, Brawn JD, Simpson SA, Esker TL, Jansen RW, Walk JW, Kershner EL, Bouzat JL, Paige KN (1998) Tracking the longterm decline and recovery of an isolated population. Science 282:1695-11698. https://doi.org/10.1126/science.282.5394.1695

Whiteley AR, Fitzpatrick SW, Funk WC, Tallmon AD (2015) Genetic rescue to the rescue. Trends Ecol Evol 30:42-49. https://doi. org/10.1016/j.tree.2014.10.009

Publisher's Note Springer Nature remains neutral with regard to jurisdictional claims in published maps and institutional affiliations. 